\title{
Report (1966-1970) of the Subcommittee on Taxonomy of Vibrios to the International Committee on Nomenclature of Bacteria
}

The membership of the subcommittee during the period covered by this report was as follows: R. Hugh (Chairman), J. C. Feeley (Secretary), C. R. Manclark, S. Mukerjee, and R. Sakazaki.

The minutes of the first meeting of the subcommittee were published in the International Journal of Systematic Bacteriology 16: 135-142.

The subcommittee has been unable to meet since 29 January 1965; however, the subcommittee has made five recommendations as a result of mail ballots.

Amended provisional description of Vibrio Pacini 1854. Gram-negative, asporogenous rods which have a single, rigid curve or which are straight. Motile by means of a single, polar flagellum. Produce indophenol oxidase and catalase. Ferment glucose without gas production. Acidity is produced from glucose by the Embden-Meyerhof glycolytic pathway. The guanine plus cytosine in the deoxyribonucleic acid of Vibrio species is within the range of 40 to 50 moles per cent.

Vibrio cholerae Pacini 1854. $V$. cholerae strains produce L-lysine and L-ornithine decarboxylases; L-arginine dihydrolase and hydrogen sulfide (Kligler iron agar) are not produced. The guanine plus cytosine in the deoxyribonucleic acid of $V$. cholerae is approximately 47 moles per cent. $V$. cholerae includes strains which may or may not elicit the cholera-red (nitroso-indole) reaction, may or may not be hemolytic, may or may not be sensitive to polymyxin B, may or may not be agglutinated by Gardner and Venkatraman $O$ group I antiserum, and may or may not be lysed by Mukerjee $V$. cholerae bacteriophages I, II, III, IV, and V.

Vibrio cholerae serotypes. $V$. cholerae strains have a common $\mathrm{H}$ antigen and have been serologically grouped into 39 serotypes according to their $\mathrm{O}$ antigens (Sakazaki et al., Jap. J. Med. Sci. Biol. 23: 13-20). Strains agglutinated by Gardner and Venkatraman $O$ group $I$ antiserum are in serotype $I$ and are the principal cause of cholera in man. An $M$ antigen may obscure the agglutinability of mucoid strains of $V$. cholerae. $V$. cholerae strains in the $\mathrm{R}$ (rough) form cannot be serotyped.

Vernacular names and jargon are unsatisfactory substitutes for Latin names of Vibrio species. In an attempt to sharpen the meaning of concepts, convey precise ideas, and expedite international communication in the scientific community, laboratory jargon, vernacular names, and colloquial terms should be discouraged in scientific publications. Specific reference is made to the following and related terms: cholera bacillus, cholera-like vibrios, agglutinable vibrios, nonagglutinable (NAG) vibrios, noncholera vibrios (NCV), vibrios of El Tor cholera, vibrios of classical cholera, El Tor cholera vibrios, El Tor vibrios, classical vibrios, cholerigenic vibrios, choleriform vibrios, water vibrios, paracholera vibrios, and Heiberg vibrios.

Vibrio fetus Smith and Taylor 1919. V. fetus and related microaerophilic vibrios should be removed from the genus Vibrio Pacini. Sebald and Véron (Ann. Inst. Pasteur 105:897-910) proposed that $V$. fetus be transferred to the genus Campylobacter as $C$. fetus, the type species of the genus.

The subcommittee plans to enumerate the minimal characters necessary for the identification of Vibrio species.

R. Hugh, Chairman

J. C. Feeley, Secretary 